\title{
Dynamic response of rock slope with anti-dip weak interlayer and its influencing factors under seismic actions
}

\author{
Tong Wang ${ }^{1} \cdot$ Chengliang Gao $^{1} \cdot$ Fei Huang ${ }^{1} \cdot$ Di Peng $^{1} \cdot$ Shuwen Tian ${ }^{1} \cdot$ Huilan $\mathrm{Li}^{1}$
}

Received: 13 November 2020 / Accepted: 6 February 2021 / Published online: 4 March 2021

(C) The Author(s) 2021

\begin{abstract}
The load features of ground motion are mainly reflected by three factors: amplitude, frequency, and duration. The combination of these factors determines the response of rock-soil mass and the structure safety under seismic load. By finite element method, this paper analyzes the influence of the three factors of ground motion on the dynamic response of a slope. The analysis shows that the slope displacement increased with the elevation from the bottom. The anti-dip fault puts the slope in an unfavorable deformation state. Due to the large residual deformation in the fault zone, a large displacement occurred on the slope top. It was also learned that the adjustment of amplitude only leads to proportional growth in the absolute value of the acceleration of the slope. Under the same conditions, the dynamic responses in different parts of the target slope are not greatly affected by the changing amplitude, but depend more on the material and spectral features of the rock-soil mass. The research results provide a reference for the evaluation and prediction of slope seismic stability and the evolution of slope damage under earthquakes with different frequencies, amplitudes, and durations.
\end{abstract}

Keywords Rock slope $\cdot$ Weak interlayer $\cdot$ Dynamic response $\cdot$ Seismic actions $\cdot$ Influencing factors

\section{Introduction}

To scientifically evaluate the seismic stability of a slope, the prerequisite is to clarify the dynamic response and change law of the slope under seismic actions. In general, the main parameters for evaluating the seismic stability of a slope include acceleration, velocity, and displacement. Among them, the acceleration response of the slope and its distribution law are the basic data for evaluating the dynamic response of the slope under the action of seismic load (Marzoratia et al. 2012; NovaRoessig and Sitar 2016; Li and Cai 2020; Li et al. 2020; Luo et al. 2020; Zhao and Dong 2020; Zhao et al. 2019; Shibata and Nagao 2020; Michalowski and You 2000).

The dynamic response of slopes differs with the rock-soil materials and structures ( $\mathrm{Li}$ and Cai 2020; Marzoratia et al.

Responsible Editor: Ahmed Farouk

This article is part of the Topical Collection on Big Data and Intelligent Computing Techniques in Geosciences

Tong Wang

wt09143323@163.com

1 School of Prospecting \& Surveying Engineering, Changchun Institute of Technology, Changchun 130061, China
2012; Jibson 2011; Azizian and Popescu 2006). In the same slope, the dynamic response varies from part to part. Therefore, this paper deploys lots of monitoring points in different parts and directions of a slope, facilitating the calculation and analysis on the dynamic response of the slope and its influencing factors.

The dynamic response of slopes has attracted the attention of many scholars (Taiebat et al. 2011; Jibson et al. 2000). For example, Bo et al. (2001) studied the seismic response and dynamic stability of soil slopes. Using Fast Lagrangian Analysis of Continua in 3 Dimensions (FLAC3D), Liu et al. (2004) investigated the influence of the slope shape on the distribution of dynamic response on the slope profile. $\mathrm{Bi}$ et al. (2009) used ABAQUS to establish a dynamic numerical model for a homogeneous soil slope and analyzed the dynamic response of the slope under seismic actions. Yan et al. (2011) relied on the finite element method to explore the resonance law of a slope under bidirectional seismic waves.

Drawing on the relevant literature, this paper combs the research data on the 2008 Sichuan earthquake and sorts out the strong earthquake records near Hanyuan County, the epicenter of the earthquake. Then, an ANSYS simulation was carried out on the large ancient landslide in the Beihou Mountain of Hanyuan County. The resonance features, 
Fig. 1 The time history of ground motion input

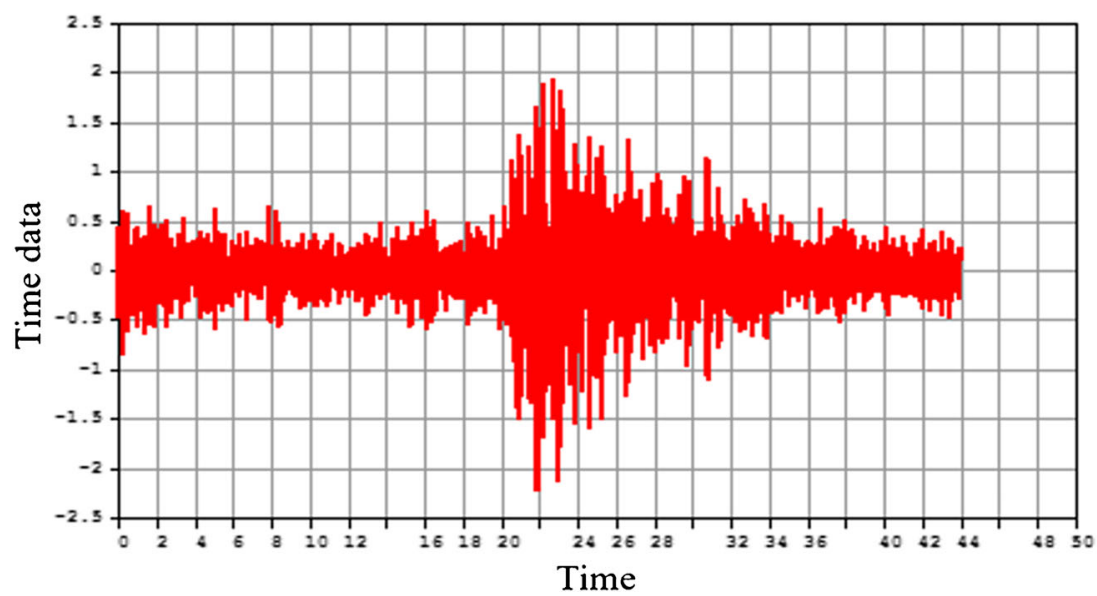

dynamic response, and its influencing factors of the slope were investigated under seismic actions, and the highintensity abnormality in Hanyuan County was explained from the angle of resonance. In addition, finite element method was adopted to discuss the influence of seismic amplitude, frequency, and duration on the dynamic response of the slope.

\section{General law of slope dynamic response}

The dynamic response of a slope mainly manifests in the acceleration, velocity, and displacement in different parts (monitoring points) of the slope. Among them, the response and distribution of acceleration are the bases for analyzing the dynamic response of the slope under seismic actions. According to the Code for Seismic Design of Buildings (GB50011-2010), the ground motion was inputted as shown in Fig. 1.

To accurately describe the dynamic response of the target slope, a total of 14 monitoring points were set up at different positions of the slope (i.e., slope surface, sliding surface, and slope body). Figure 2 shows the specific location and serial number of each monitoring point. Table 1 provides the

Table 1 The locations of monitoring points

\begin{tabular}{llllll}
\hline $\begin{array}{l}\text { Serial } \\
\text { number }\end{array}$ & $\begin{array}{l}\text { Distance } \\
\text { from right } \\
\text { boundary } \\
(\mathrm{m})\end{array}$ & $\begin{array}{l}\text { Elevation } \\
\text { from } \\
\text { bottom } \\
(\mathrm{m})\end{array}$ & $\begin{array}{l}\text { Serial } \\
\text { number }\end{array}$ & $\begin{array}{l}\text { Distance } \\
\text { from right } \\
\text { boundary } \\
(\mathrm{m})\end{array}$ & $\begin{array}{l}\text { Elevation } \\
\text { from } \\
\text { bottom } \\
(\mathrm{m})\end{array}$ \\
\hline 1 & 400 & 1000 & 2 & 730 & 960 \\
9 & 400 & 920 & 3 & 840 & 940 \\
10 & 400 & 800 & 4 & 1000 & 800 \\
11 & 400 & 750 & 5 & 1300 & 690 \\
12 & 400 & 700 & 6 & 680 & 900 \\
13 & 400 & 500 & 7 & 750 & 850 \\
14 & 400 & 300 & 8 & 870 & 800 \\
\hline
\end{tabular}

distances from each monitoring point of the calculation model to the bottom and the right boundary of the slope.

\section{Acceleration response}

To analyze the change law of slope dynamic response in elevation, seven monitoring points $(1,9,10,11,12,13$, and 14) in the slope body were selected along the vertical direction and used. Their distances from the bottom are about $1000 \mathrm{~m}$, $960 \mathrm{~m}, 800 \mathrm{~m}, 750 \mathrm{~m}, 700 \mathrm{~m}, 500 \mathrm{~m}$, and $300 \mathrm{~m}$, respectively. Figure 3 presents the time history of acceleration at each monitoring point.

To analyze the change law of slope dynamic response along the slope surface, monitoring points $1,2,3,4$, and 5 (their distances form the right boundary are about $400 \mathrm{~m}$, $730 \mathrm{~m}, 840 \mathrm{~m}, 1000 \mathrm{~m}$, and $1300 \mathrm{~m}$, respectively) were selected, plus monitoring points 6,7 , and 8 (their distances from the right boundary are about $680 \mathrm{~m}, 750 \mathrm{~m}$, and $870 \mathrm{~m}$, respectively).

From the waveform, the acceleration responses in Fig. 3 are basically the same as the acceleration of ground motion in Fig.

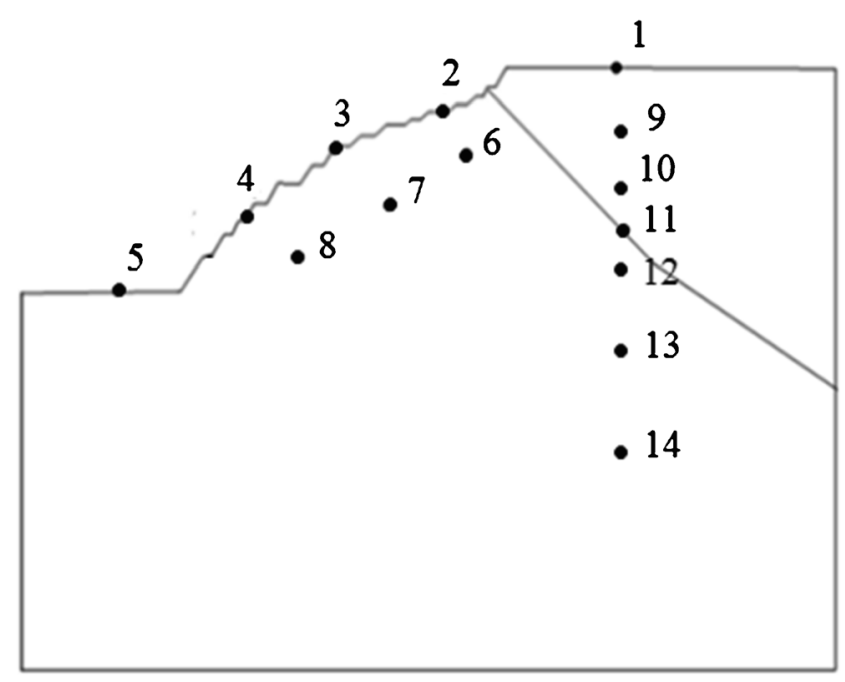

Fig. 2 The arrangement of monitoring points 
1. The only difference lies in the amplitude. In Fig. 3, the time histories of acceleration responses reflect that the force on the slope changed in an inverted U-shape, under seismic actions.

To clarify the acceleration response law of the slope under seismic actions, the peak acceleration ratio of any point in the slope body to the input ground motion was defined as the peak ground acceleration (PGA) amplification factor [2], which clearly reveals the law of acceleration response of the slope and its degree of amplification. Tables 2 and 3 present the peak accelerations of vertical monitoring points and surface monitoring points, respectively.

Figures 4 and 5 display the change laws of the PGA amplification factor in the vertical direction and in the horizontal direction, respectively.

In the vertical direction, the anti-dip fault $\mathrm{F}_{1}$ reflects and refracts the ground motion. As a result, the PGA amplification

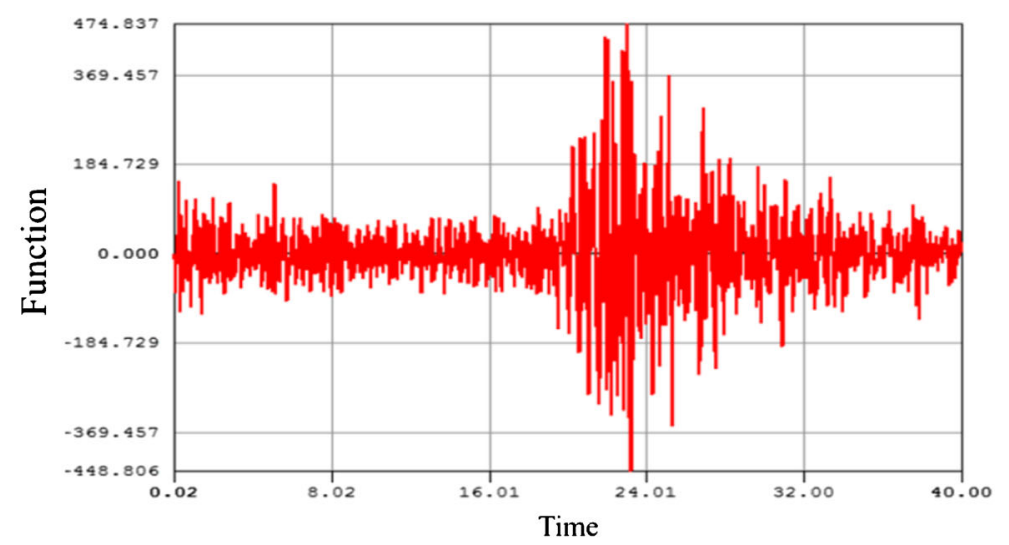

Acceleration response at monitoring point 1

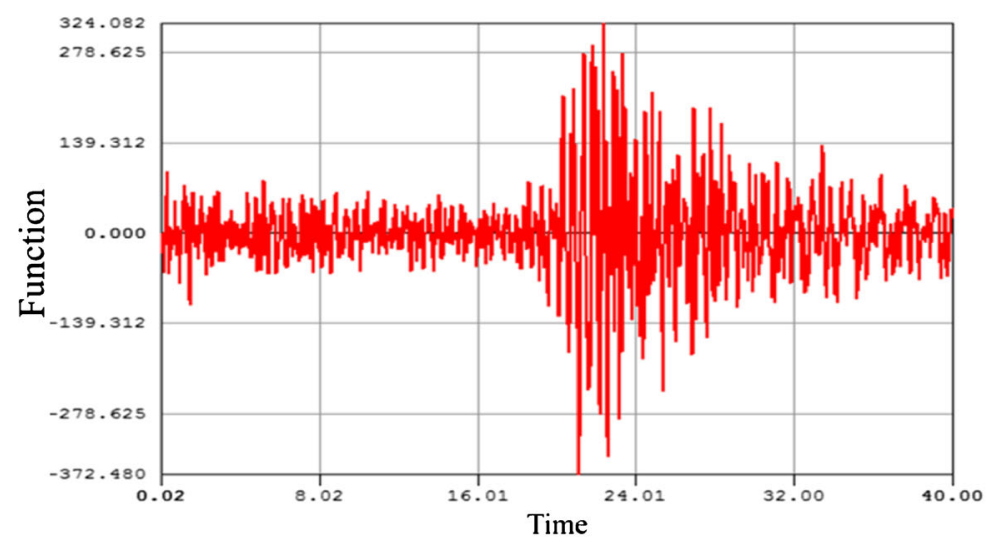

Acceleration response at monitoring point 9

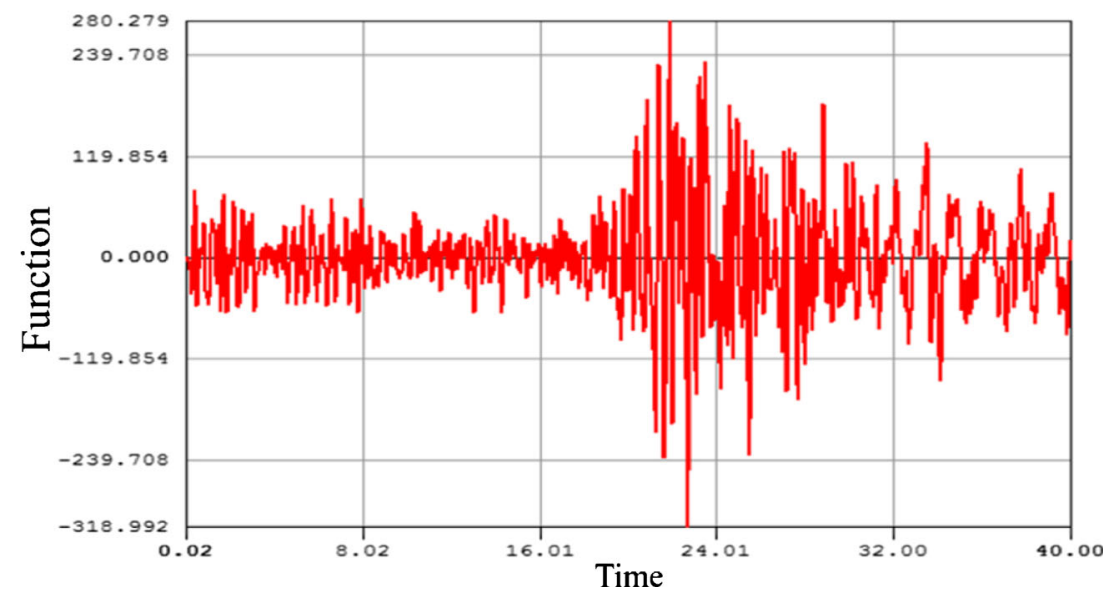

Acceleration response at monitoring point 10

Fig. 3 The acceleration responses at vertical monitoring points (acceleration, $\mathrm{cm} / \mathrm{s}^{2}$; time, $\mathrm{s}$ ) 


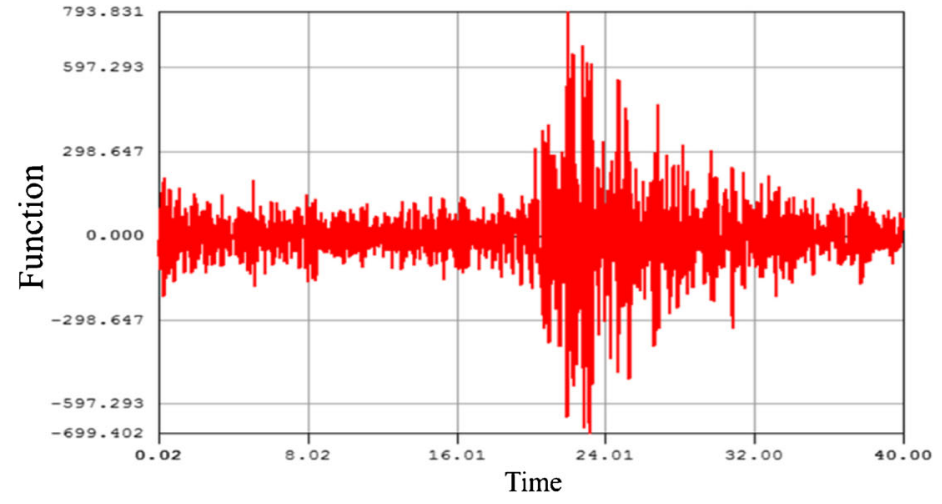

Acceleration response at monitoring point 11

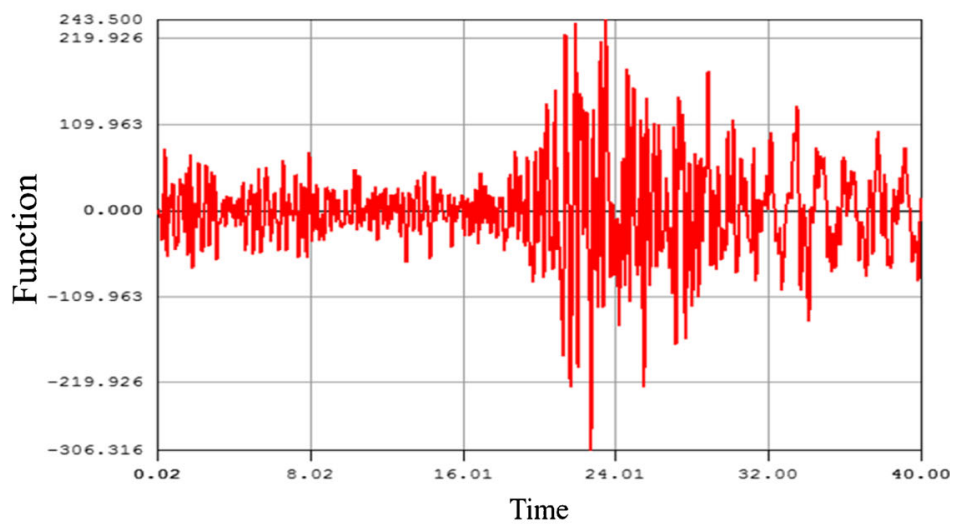

Acceleration response at monitoring point 12

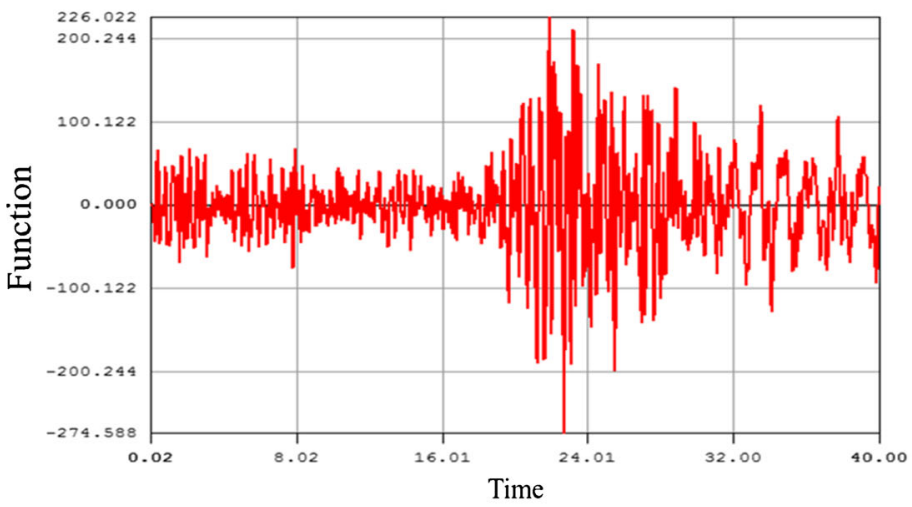

Acceleration response at monitoring point 13

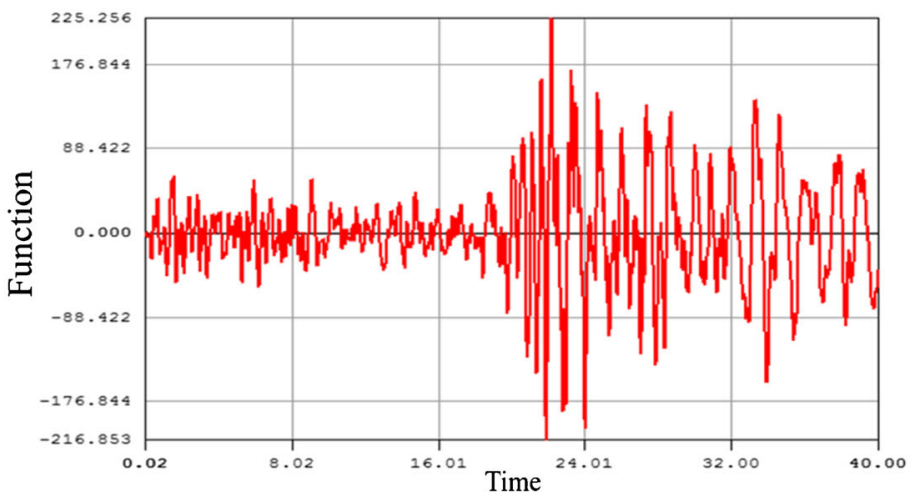

Acceleration response at monitoring point 14

Fig. 3 (continued) 
Table 2 The peak accelerations of vertical monitoring points

Table 3 The peak accelerations of surface monitoring points

Fig. 4 The change law of PGA amplification factor in the vertical direction

Fig. 5 The change law of PGA amplification factor in the horizontal direction. (a) On slope surface. (b) On sliding surface

\begin{tabular}{llllllll}
\hline Serial number & 1 & 9 & 10 & 11 & 12 & 13 & 14 \\
\hline Peak acceleration $\left(\mathrm{cm} / \mathrm{s}^{2}\right)$ & 474.8 & 372.5 & 318.9 & 793.8 & 307.0 & 274.9 & 225.3 \\
Elevation from bottom $(\mathrm{m})$ & 1000 & 920 & 800 & 750 & 700 & 500 & 300 \\
\hline
\end{tabular}

\begin{tabular}{llllllll}
\hline Serial number & 2 & 3 & 4 & 5 & 6 & 7 & 8 \\
\hline Peak acceleration $\left(\mathrm{cm} / \mathrm{s}^{2}\right)$ & 455.0 & 601.8 & 786.7 & 376.5 & 441.1 & 543.7 & 583.7 \\
Distance from right boundary $(\mathrm{m})$ & 730 & 840 & 1000 & 1300 & 680 & 750 & 870 \\
\hline
\end{tabular}
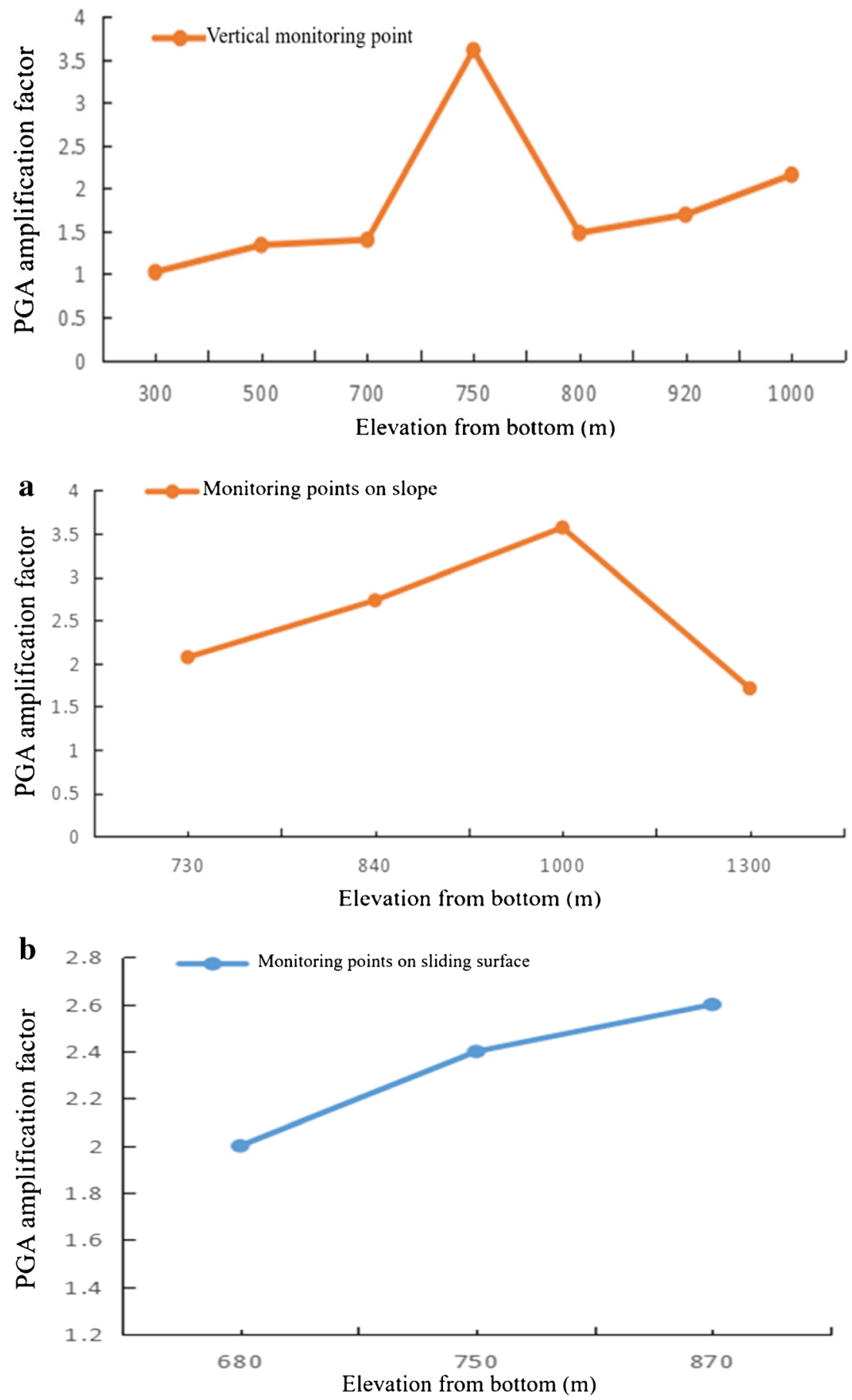
factor was not monotonously increasing with the growth in slope height. The acceleration responses of the slope concentrated on the fault, that is, the dynamic response of acceleration changed suddenly at the fault and gradually attenuated to the two sides. The peak seismic acceleration at the fault was magnified by 3.6 times.
Fig. 6 The displacement responses at vertical monitoring points (displacement, $\mathrm{cm}$; time, s)

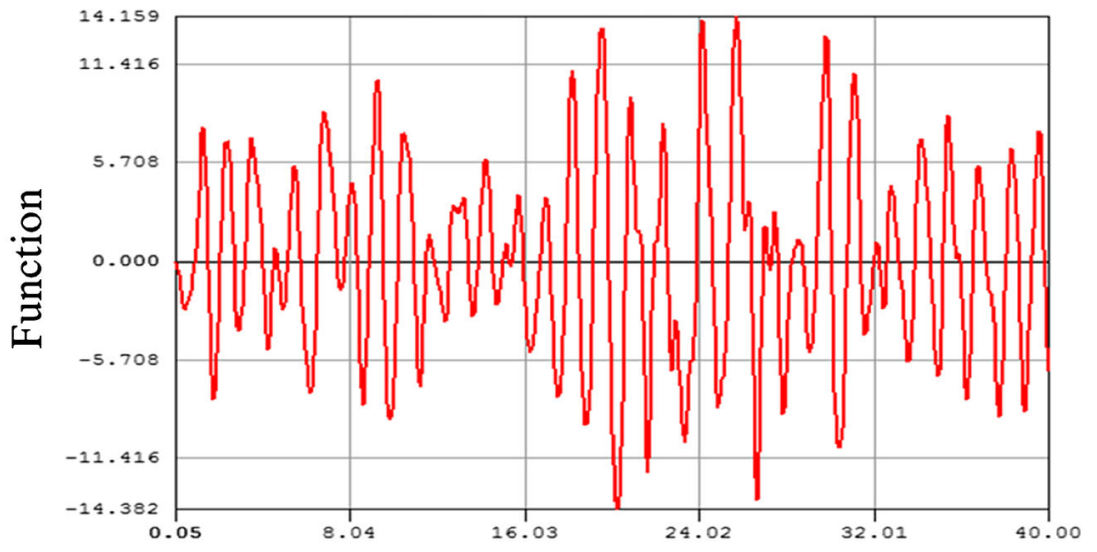

Time

Displacement response at monitoring point 1

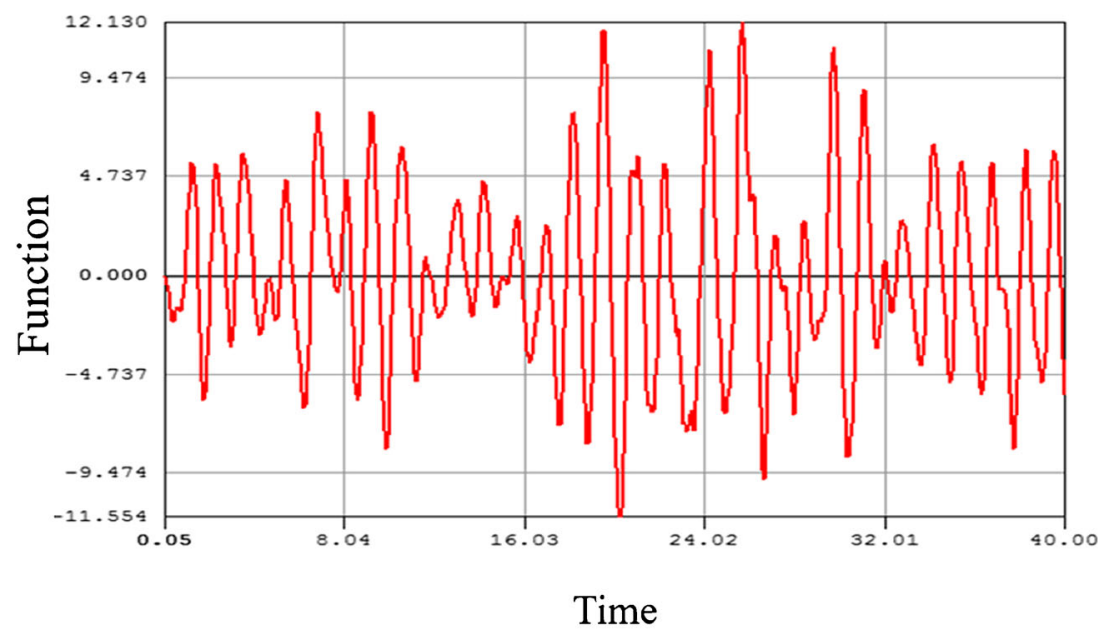

Displacement response at monitoring point 9

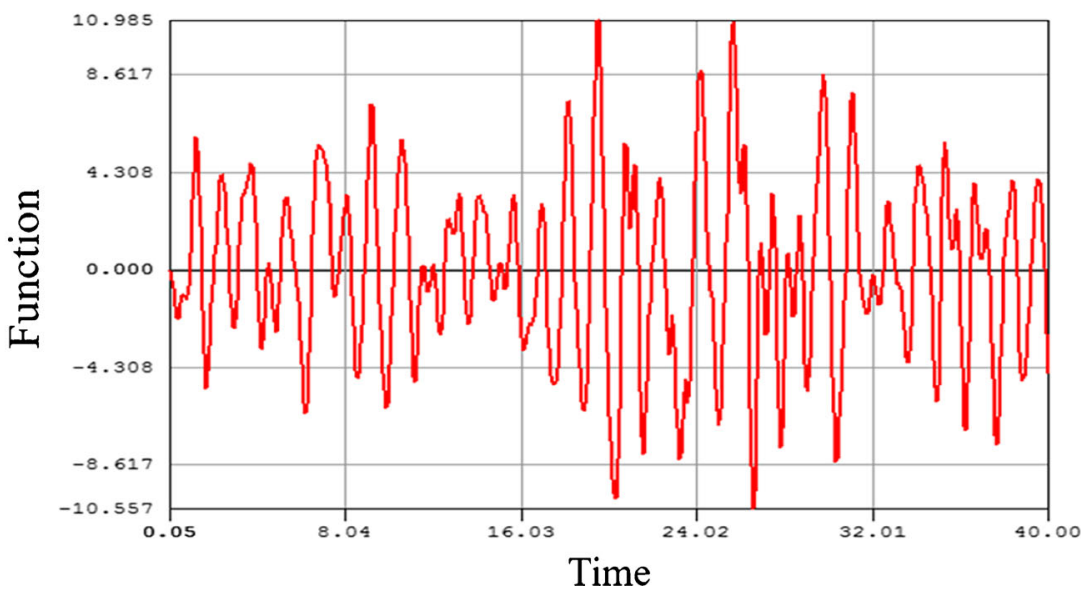

Displacement response at monitoring point 10 

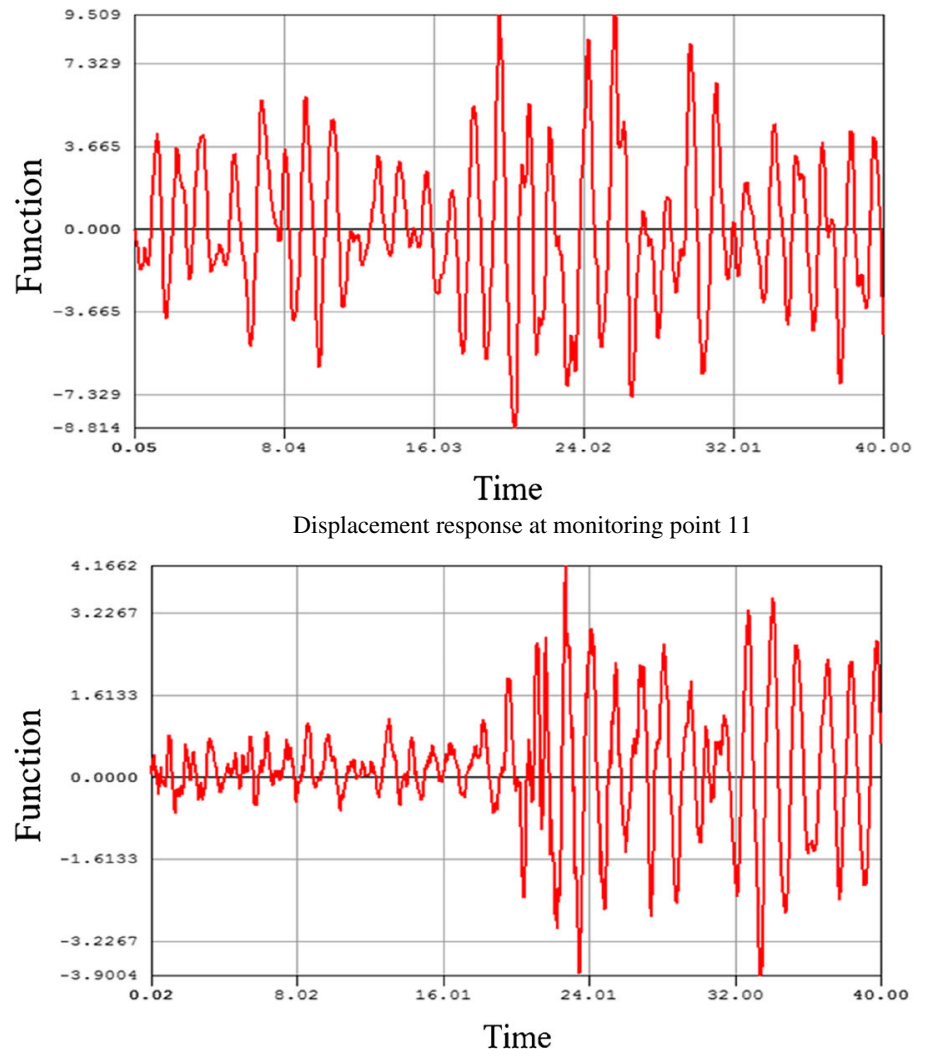

Displacement response at monitoring point 12

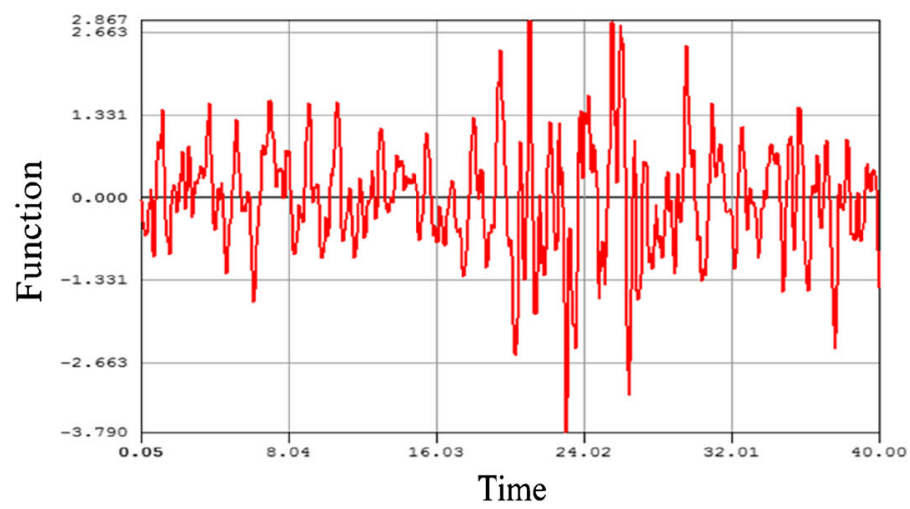

Displacement response at monitoring point 13

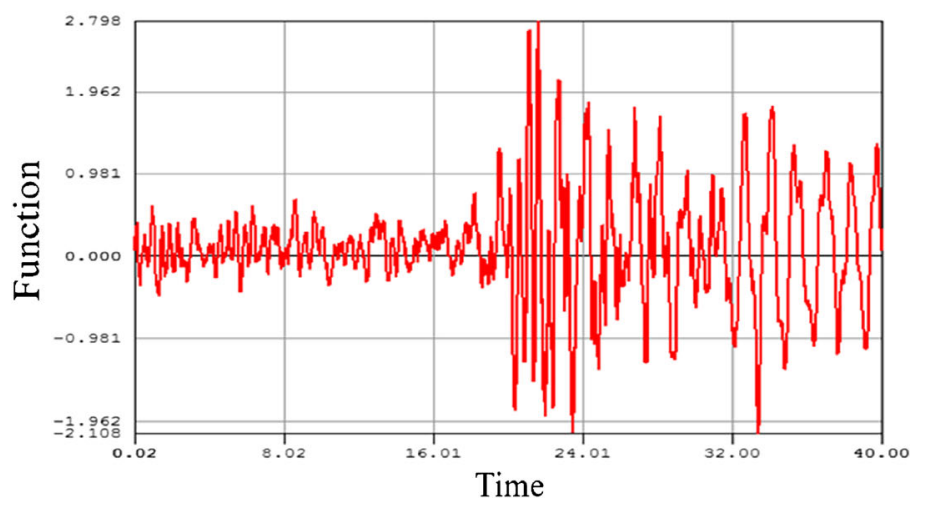

Displacement response at monitoring point 14

Fig. 6 (continued) 
Fig. 7 The displacement responses at surface monitoring points (displacement, $\mathrm{cm}$; time, $\mathrm{s}$ )

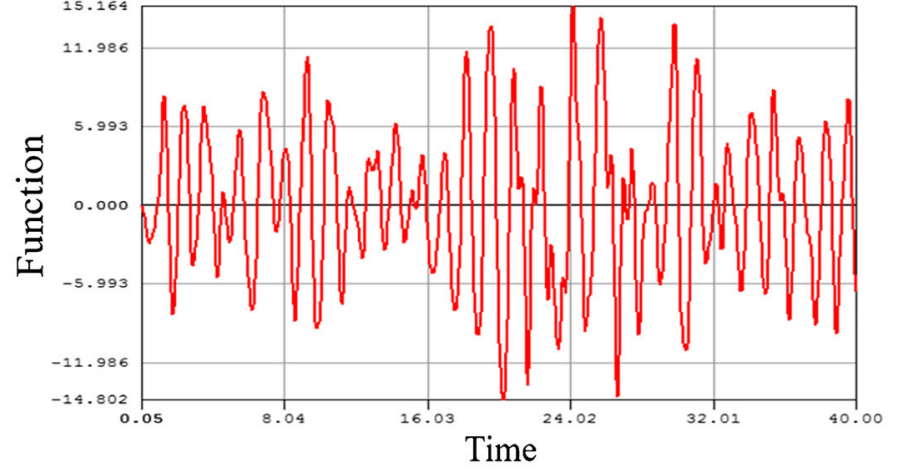

Displacement response at monitoring point 2

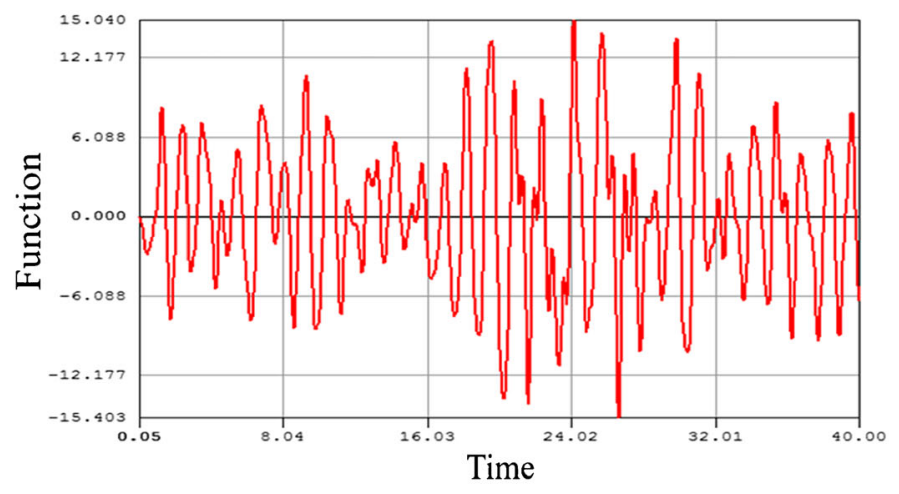

Displacement response at monitoring point 3

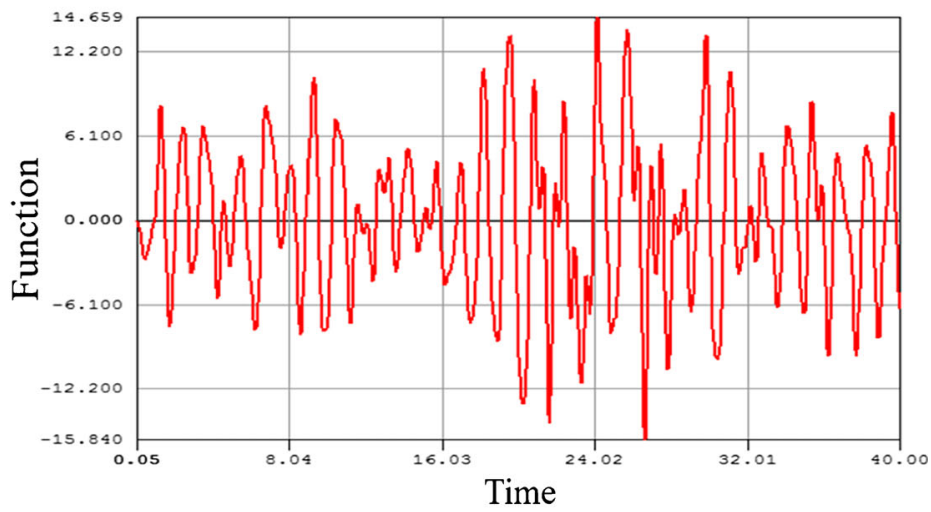

Displacement response at monitoring point 4

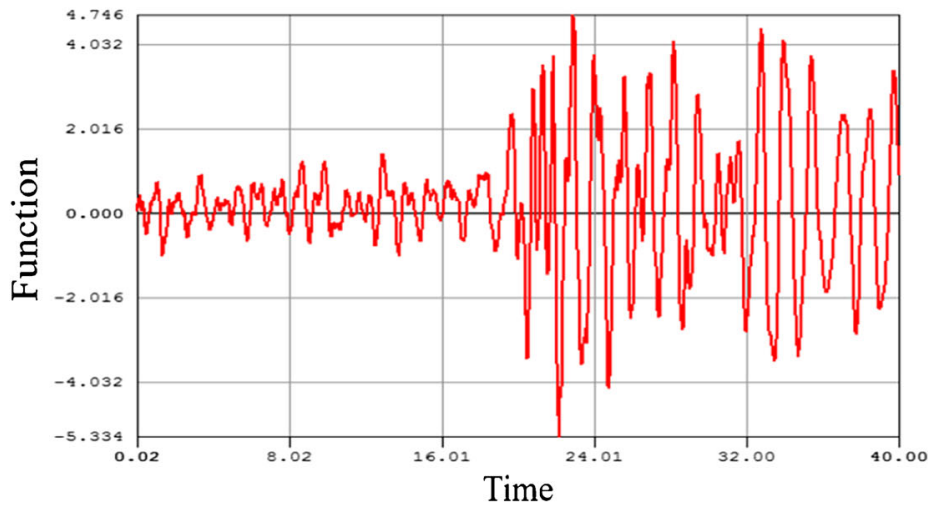

Displacement response at monitoring point 5 


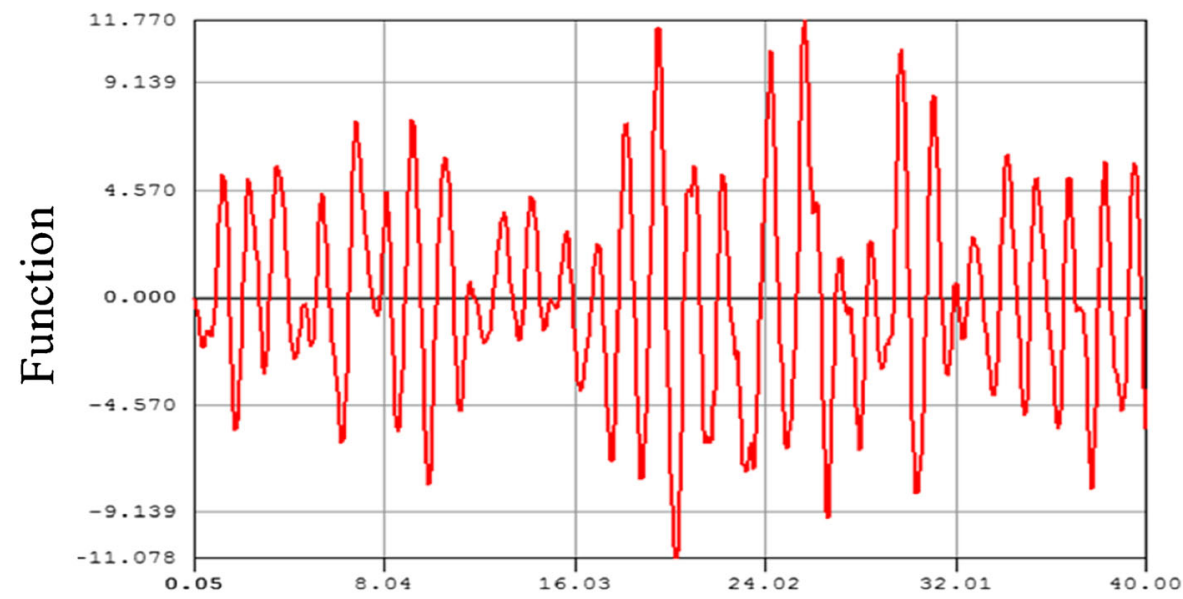

Time

Displacement response at monitoring point 6

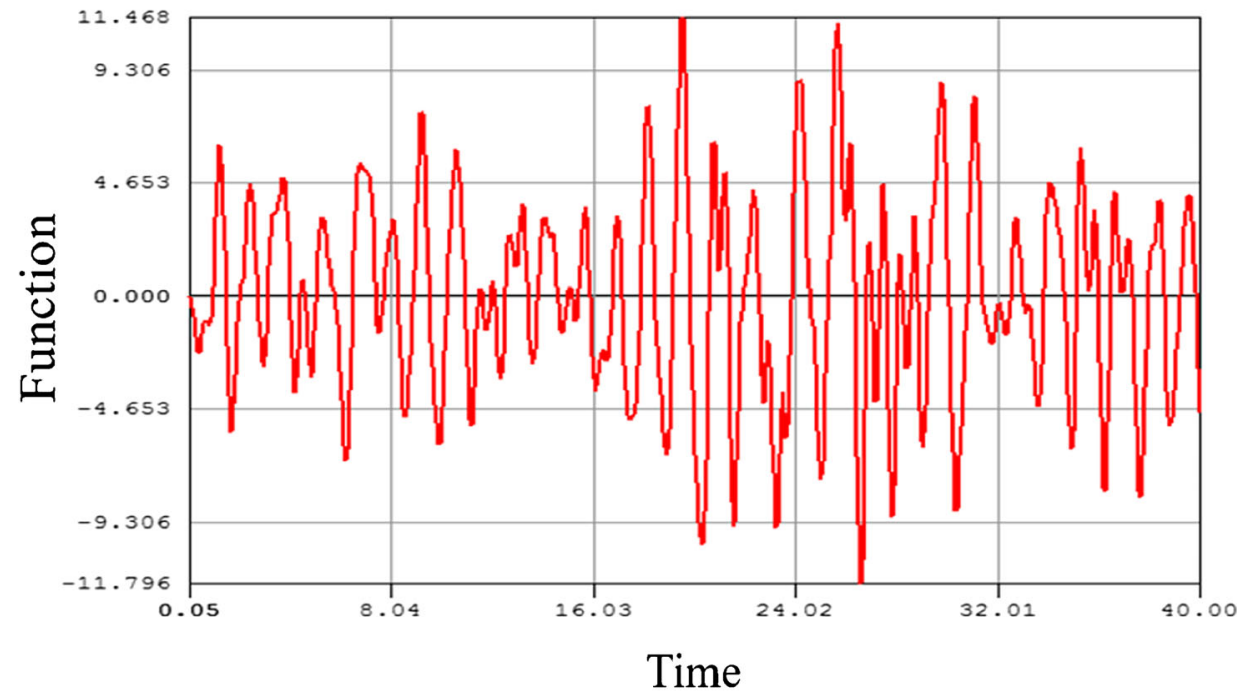

Displacement response at monitoring point 7

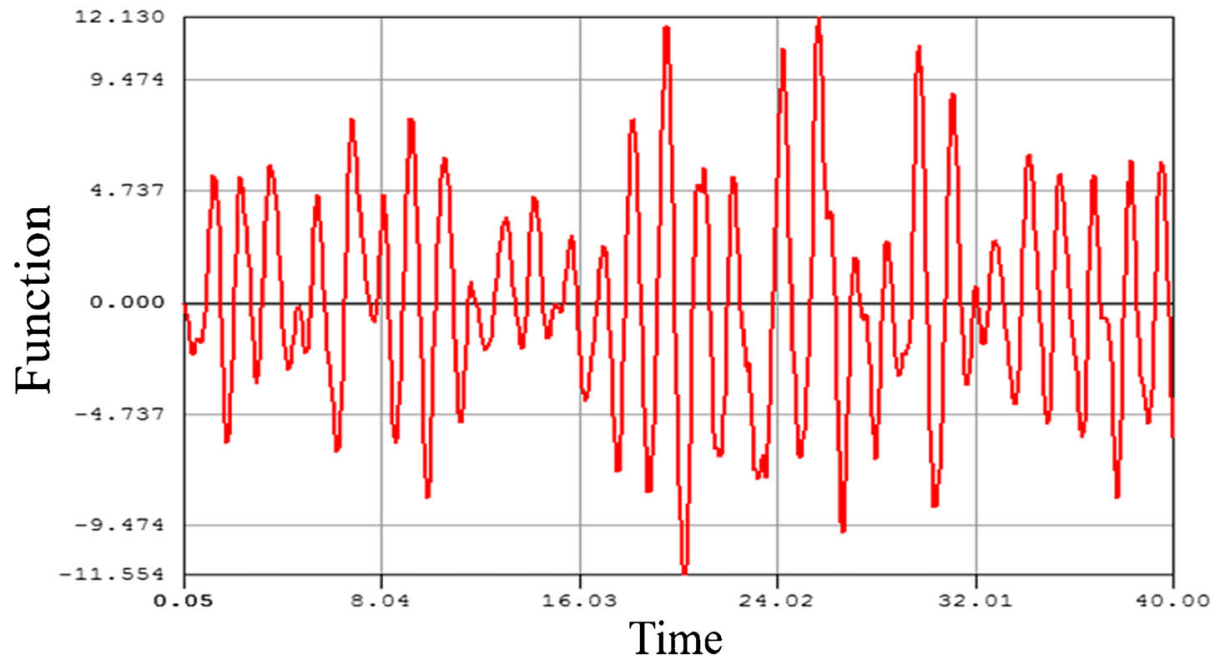

Displacement response at monitoring point 8

Fig. 7 (continued) 
Table 4 The peak displacements of vertical monitoring points

\begin{tabular}{llllllll}
\hline Serial number & 1 & 9 & 10 & 11 & 12 & 13 & 14 \\
\hline Peak displacement $(\mathrm{cm})$ & 14.38 & 12.13 & 10.98 & 9.51 & 4.20 & 3.79 & 2.79 \\
Elevation from bottom $(\mathrm{m})$ & 1000 & 920 & 800 & 750 & 700 & 500 & 300 \\
\hline
\end{tabular}

On the slope surface, the PGA amplification factor gradually increased before a steady decline. Under seismic actions, the peak acceleration appeared on the surface layer of slope shoulder, indicating that this part is the most prone to seismic damage. This is related to the structure of the slope and the lithology of each layer.

On the sliding surface, the PGA amplification factor gradually increased as the monitoring point approached the slope surface. Thus, the rock-soil mass could be easily damaged under seismic actions.

Furthermore, in the vertical direction, the refraction and superposition of the ground motion created a complex seismic wave field, causing the peak acceleration to surge on slope surface and shoulder. Thus, relatively large vertical accelerations were monitored in the two parts. The change law of vertical acceleration is similar to that of horizontal acceleration: the acceleration was amplified on the free face (slope surface) and in the vertical direction (slope top); from right to left of slope surface, the vertical acceleration tended to increase.

\section{Displacement response}

Figures 6 and 7 show the change laws of peak displacement in the vertical direction and along the slope surface, respectively.

Tables 4 and 5 present the peak displacements of vertical monitoring points and surface monitoring points, respectively.
Figures 8 and 9 display the change laws of peak displacement in the vertical direction and the horizontal direction, respectively.

In the vertical direction, the peak displacement increased with the growing elevation from the bottom. The anti-dip fault puts the slope in an unfavorable deformation state. Due to the large residual deformation in the fault zone, a large displacement occurred on the slope top. On the same elevation, the rock-soil in the hanging wall of the fault was displaced more significantly than that on the foot wall.

In the horizontal direction, the greatest displacement appeared near the slope shoulder. Comparing the vertical and horizontal displacements, it can be seen that the free face has a more significant amplification effect than the vertical direction.

\section{Influence of ground motion parameters on slope dynamic response}

\section{Influence of amplitude}

The El Centro wave was chosen for the subsequent analysis. As shown in Fig. 10, the amplitude of El Centro wave changes significantly over time. To disclose the influence of amplitude on slope dynamic response, the popular engineering approach
Table 5 The peak displacements of surface monitoring points

Fig. 8 The change law of peak displacement in the vertical direction

\begin{tabular}{llllllll}
\hline Serial number & 2 & 3 & 4 & 5 & 6 & 7 & 8 \\
\hline Peak displacement $(\mathrm{cm})$ & 15.16 & 15.40 & 15.84 & 5.33 & 11.77 & 11.84 & 13.13 \\
Distance from right boundary $(\mathrm{m})$ & 730 & 840 & 1000 & 1300 & 680 & 750 & 870 \\
\hline
\end{tabular}

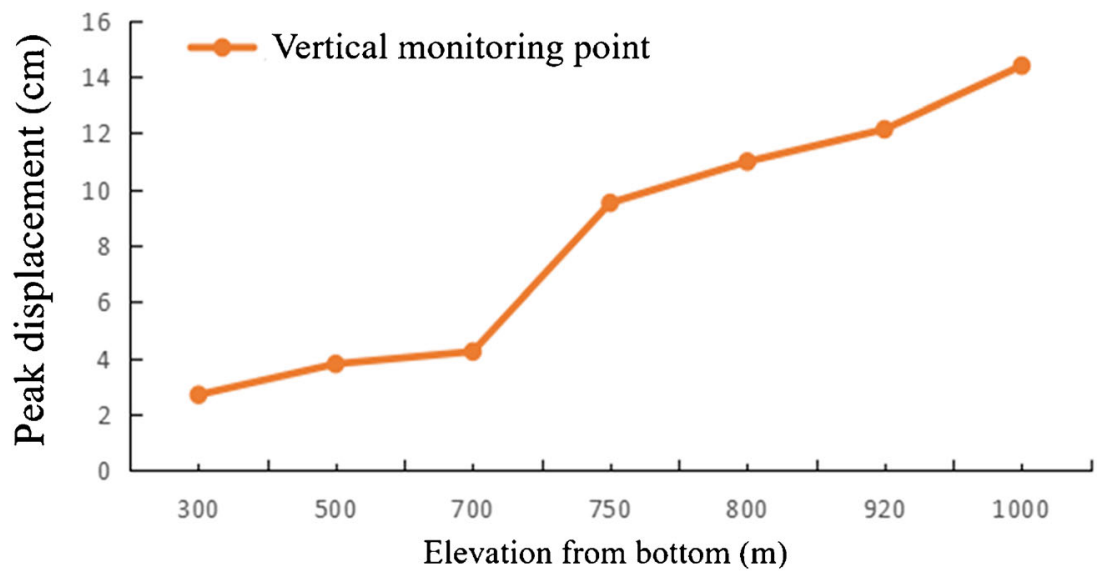


Fig. 9 The change law of peak displacement in the horizontal direction. (a) On slope surface. (b) On sliding surface
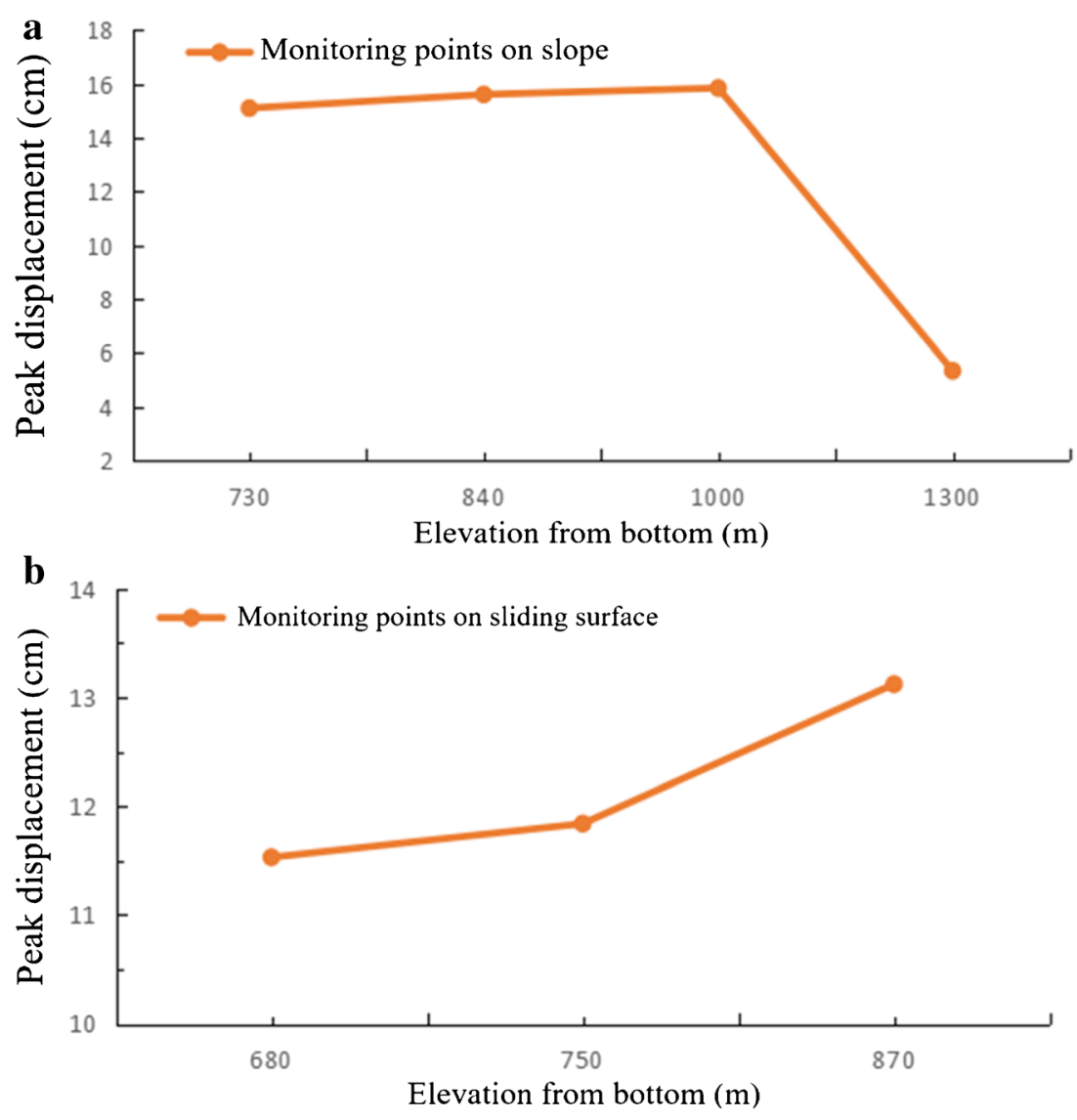

of proportional adjustment was adopted to adjust the amplitude to.

The seismic wave selected in this paper is the EI Centro wave, as shown in Fig. 3. Its amplitude changes significantly at different times. In order to study the impact of amplitude on the dynamic response of slopes, this paper adopts the most widely used proportional adjustment method in engineering. The amplitude was adjusted to $140 \mathrm{~m} / \mathrm{s}^{2}, 220 \mathrm{~m} / \mathrm{s}^{2}, 320 \mathrm{~m} / \mathrm{s}^{2}$, and $400 \mathrm{~m} / \mathrm{s}^{2}$, while the duration was maintained at $40 \mathrm{~s}$.

Figure 11 records the variations in PGA amplification factors at vertical monitoring points $1,9,10,11,12,13$, and 14

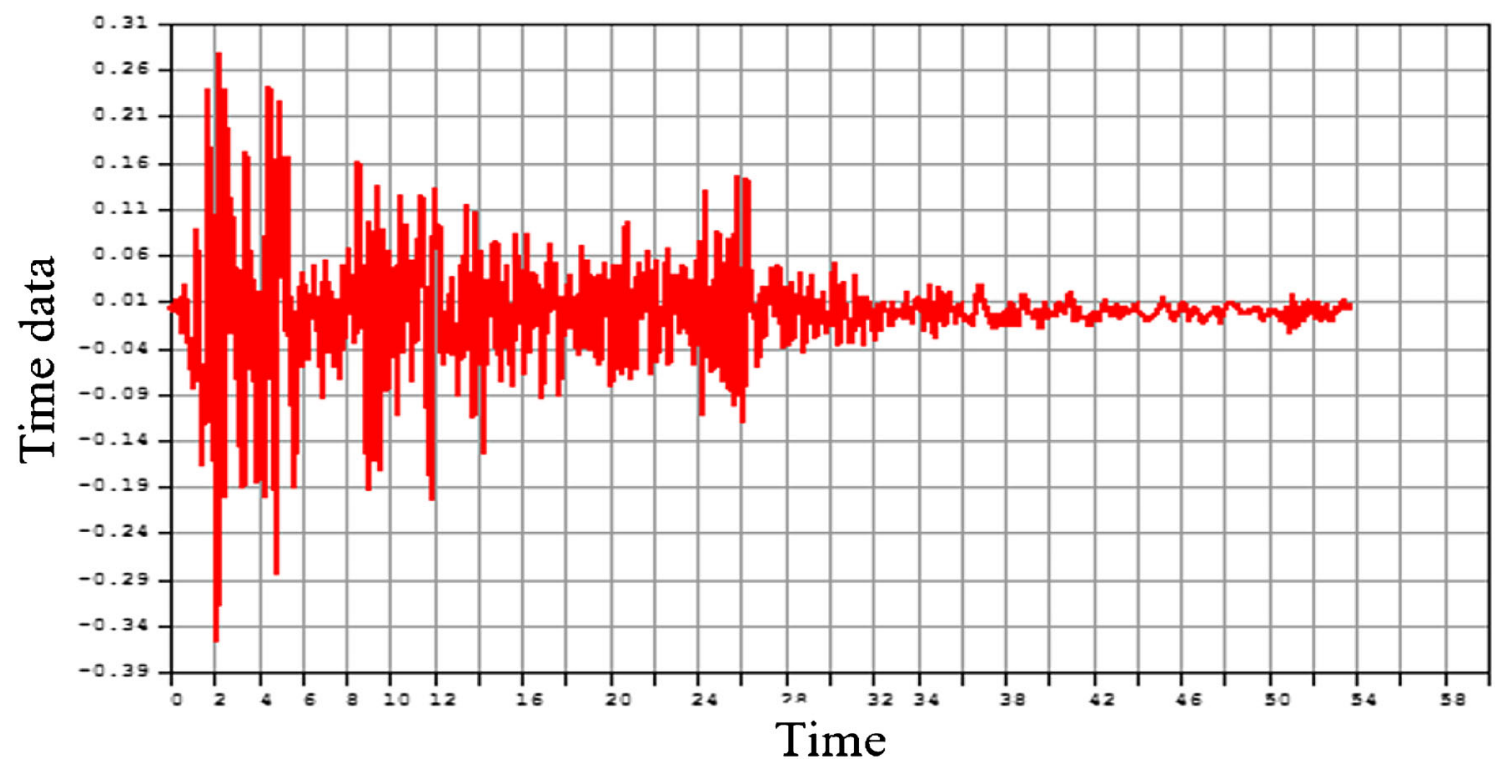

Fig. 10 The time history of the acceleration of El Centro wave 
Fig. 11 The variations in PGA amplification factors at vertical monitoring points under different amplitudes

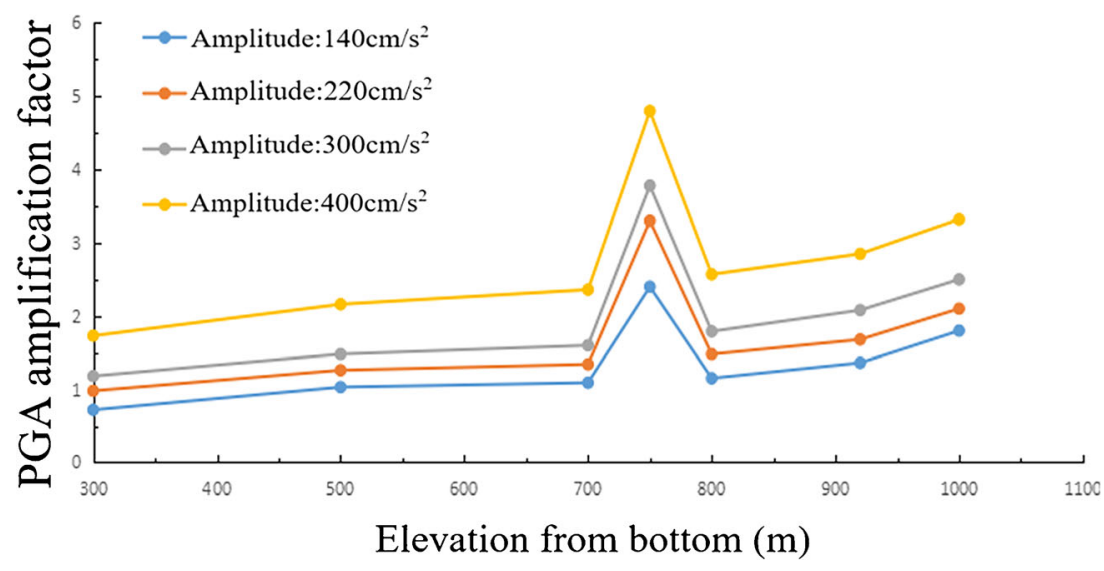

under different amplitudes. Figure 12 presents the variations in peak displacement on slope top under different amplitudes.

As shown in Fig. 11, the PGA amplification factor changed abruptly on the fault. On both sides of the fault, the PGA amplification factors at the measuring points increased proportionally with the amplitude. Thus, the adjustment of amplitude only leads to proportional growth in the absolute value of the acceleration of the slope, without changing the magnitude of the PGA amplification factor. The main reasons are as follows:

As a rock slope, the target slope has stable shear strain and stiffness. The rock slope has marked difference from soil slope in the seismic response under changing amplitudes. When the ground motion has a high amplitude, the soil slope witnesses falling stiffness and rising damping and shear strain. The variations in these parameters are
Fig. 12 The variations in peak displacement on slope top under different amplitudes

Fig. 13 The variations in PGA amplification factors at vertical monitoring points under different frequencies
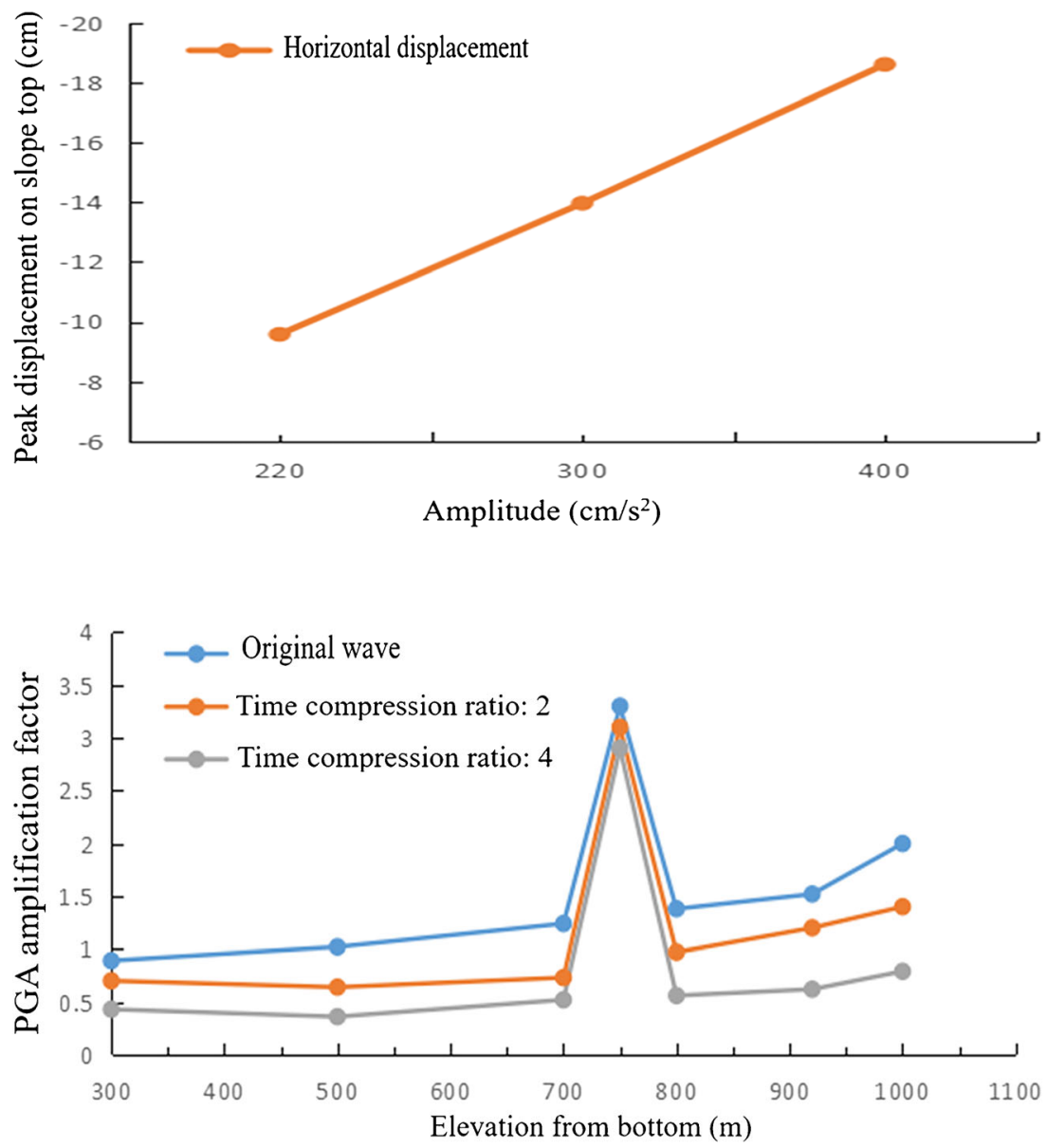
Fig. 14 The variations in peak displacement on slope top under different amplitudes

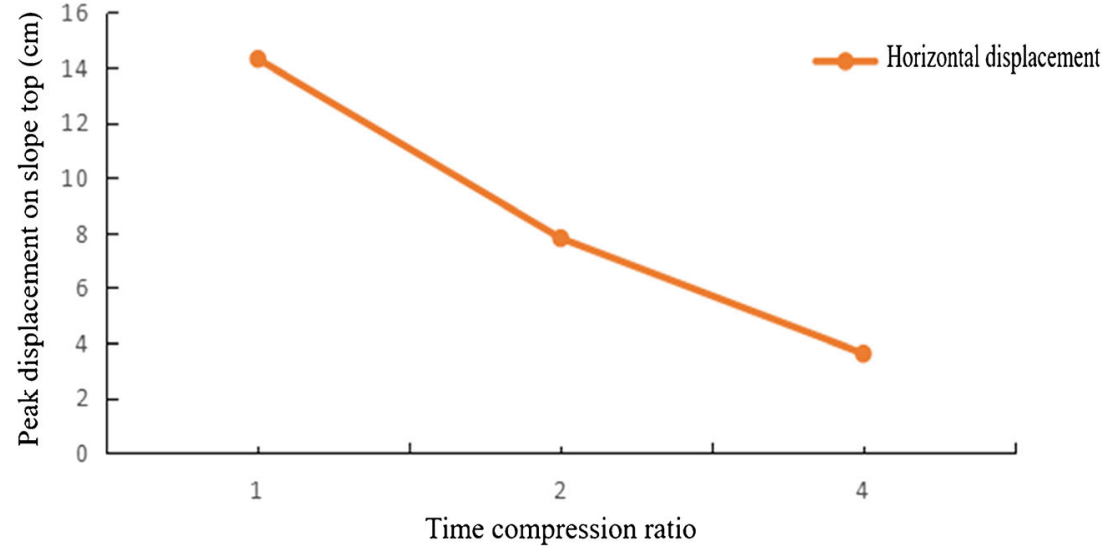

highly nonlinear. Then, the rock-soil mass in the slope has greater ability to filter seismic waves. The peak acceleration might even decrease in the lower part of the slope. Under the same conditions, the dynamic responses in different parts of the target slope are not greatly affected by the changing amplitude, but depend more on the material and spectral features of the rock-soil mass.

As shown in Fig. 12, the horizontal displacement increased almost linearly with the growing amplitude.

\section{Influence of frequency}

To analyze the influence of ground motion frequency on slope dynamic response, the El Centro wave was compressed with the time compression ratio of 1,2 , and 4, respectively. Meanwhile, the amplitude of the wave was kept at $220 \mathrm{~cm} /$ $\mathrm{s}^{2}$. The greater the time compression ratio, the shorter the cycle, and the greater the frequency. Figures 13 and 14 show the variations in PGA amplification factors at vertical monitoring points under different frequencies and the variations in peak displacement on slope top under different frequencies.

As shown in Fig. 13, with the growth in time compression ratio (i.e., the frequency of ground motion), the PGA amplification factors at all measuring points on slope surface exhibited a declining trend. The largest PGA amplification factor was measured when the input frequency equaled the frequency of the original wave. This is because the original wave has the lowest frequency, which is the most obviously amplified by the slope body. The higher the frequency, the greater the energy in the high-frequency band. The rock-soil mass can effectively filter such a ground motion. That is why the PGA amplification factor decreased.

As shown in Fig. 14, the peak displacement decreased with the growing frequency of the ground motion. The reason is that high-frequency ground motion has a relatively small acceleration and short duration due to the compression.

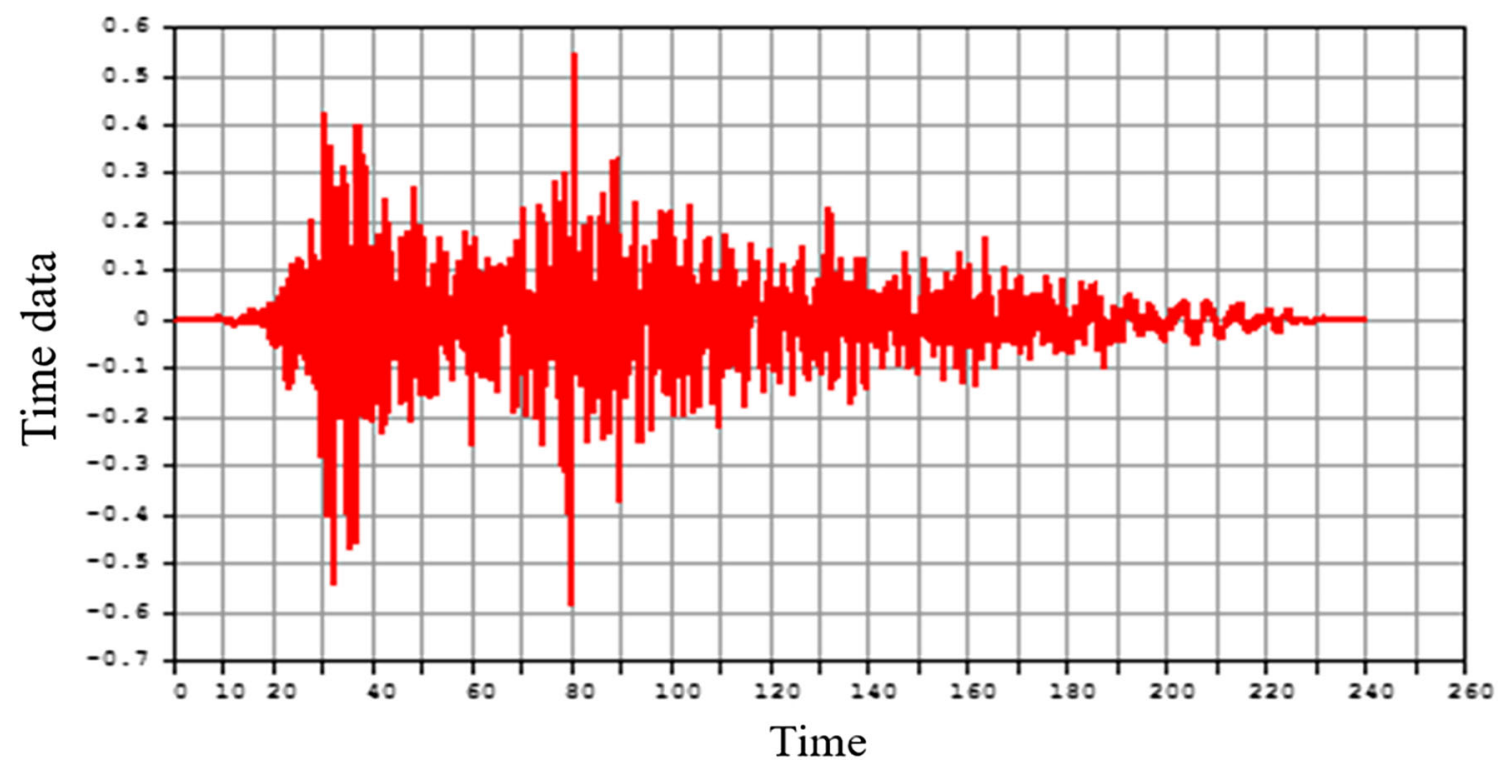

Fig. 15 The time history of the acceleration of H24-II-2 wave 


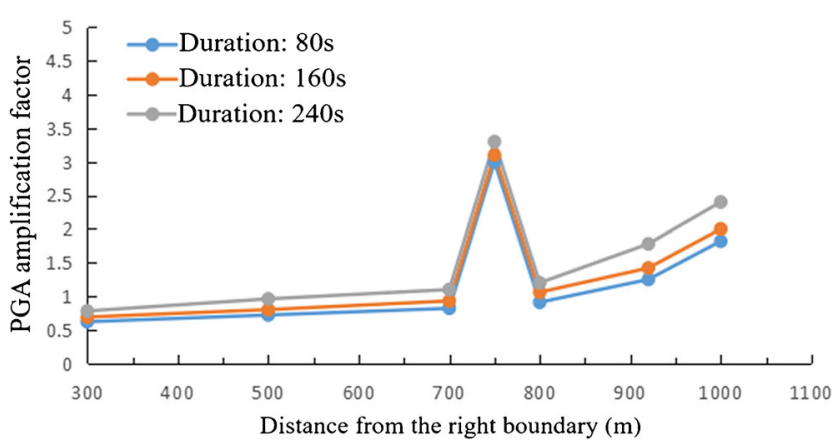

Fig. 16 The variations in PGA amplification factors in the vertical direction under different durations

\section{Influence of duration}

This section selects the H24-II-2 wave, which has a relatively long duration (Fig. 15). The long duration is favorable for our analysis on the influence of duration. The duration of the wave was set to $80 \mathrm{~s}, 160 \mathrm{~s}$, and $240 \mathrm{~s}$, respectively, while the amplitude was maintained at $220 \mathrm{~cm} / \mathrm{s}^{2}$.

Figures 16 and 17 present the variations of PGA amplification factors in the vertical and horizontal directions under different durations, respectively.

From the above figures, it can be seen that the PGA amplification factor did not exhibit any obvious law, i.e., the duration of ground motion has relatively small impact on the peak displacement of the slope body.

\section{Conclusions}

This paper analyzes the seismic stability of the large ancient landslide in the Beihou Mountain of Hanyuan County, summarizes the law of dynamic response of the slope under seismic actions, and explores how the dynamic response is affected by the three factors of ground motion. To accurately describe the dynamic response of the target slope, a total of 14 monitoring points were set up at different positions of the slope (i.e., slope surface, sliding surface, and slope body). The main conclusions are as follows:

(1) $n$ the vertical direction, the anti-dip fault $F_{1}$ reflects and refracts the ground motion. As a result, the PGA amplification factor was not monotonously increasing with the growth in slope height. The acceleration responses of the slope concentrated on the fault, that is, the dynamic response of acceleration changed suddenly at the fault and gradually attenuated to the two sides. The peak seismic acceleration at the fault was magnified by 3.6 times. The anti-dip fault puts the slope in an unfavorable deformation
Fig. 17 The variations in PGA amplification factors in the horizontal direction under different durations. (a) On slope surface. (b) On sliding surface
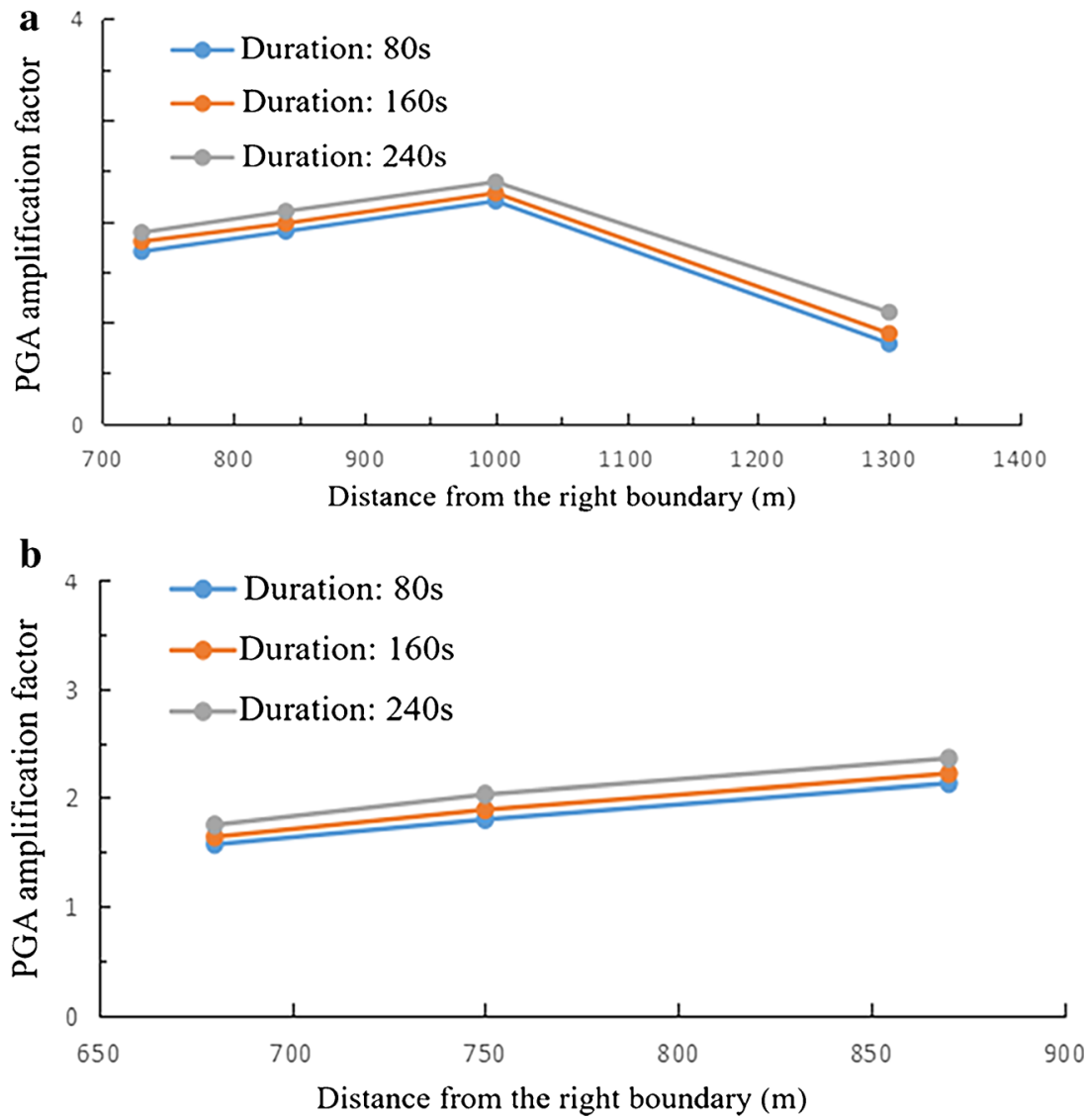
state. Due to the large residual deformation in the fault zone, a large displacement occurred on the slope top.

(2) The adjustment of amplitude only leads to proportional growth in the absolute value of the acceleration of the slope. On both sides of the fault, the PGA amplification factors at the measuring points increased proportionally with the amplitude. But their distribution did not change on the slope profile. Under the same conditions, the dynamic responses in different parts of the target slope are not greatly affected by the changing amplitude, but depend more on the material and spectral features of the rock-soil mass.

(3) With the growth in time compression ratio (i.e., the frequency of ground motion), the PGA amplification factors at all measuring points on slope surface exhibited a declining trend. The peak displacement decreased with the growing frequency of the ground motion. The duration has an insignificant impact on the peak acceleration of the slope body.

(4) The rock-soil mass in the slope amplifies the lowfrequency part and filters the high-frequency part of the input ground motion. In addition, the free face of the slope can reflect the ground motion. Under the two factors, the acceleration on the slope shoulder surged up.

Funding This work was supported by the Science and Technology Innovation Fund for Small and Medium-Sized Enterprises (Grant No. 320180025) and Department of Education, Jilin Province, China (Grant No. JJKH20191268KJ).

Open Access This article is licensed under a Creative Commons Attribution 4.0 International License, which permits use, sharing, adaptation, distribution and reproduction in any medium or format, as long as you give appropriate credit to the original author(s) and the source, provide a link to the Creative Commons licence, and indicate if changes were made. The images or other third party material in this article are included in the article's Creative Commons licence, unless indicated otherwise in a credit line to the material. If material is not included in the article's Creative Commons licence and your intended use is not permitted by statutory regulation or exceeds the permitted use, you will need to obtain permission directly from the copyright holder. To view a copy of this licence, visit http://creativecommons.org/licenses/by/4.0/.

\section{References}

Azizian A, Popescu R (2006) Three-dimensional seismic analysis of submarine slopes. Soil Dyn Earthq Eng 26(9):870-887

Bi ZW, Zhang M, Jin F, Ding DX (2009) Dynamic response of slopes under earthquakes. Rock Soil Mech 30:180-183

Bo JS, Xu GD, Jing LP (2001) Seismic response and dynamic stability analysis of soil slopes. Earthq Eng Eng Vib 21(2):117-120

Jibson RW (2011) Methods for assessing the stability of slopes during earthquakes - a retrospective. Eng Geol 122(1-2):43-50

Jibson RW, Harp EL, Michael JA (2000) A method for producing digital probabilistic seismic landslide hazard maps. Eng Geol 58(3-4):271289

Li C, Cai Y (2020) Effect of soil strength degradation on slope stability. International Journal of Design \& Nature and Ecodynamics 15(4): 483-489

Li JL, Zhang SR, Wang SL, Liu ZH, Hao YZ (2020) Shaking table tests on the seismic response of a columnless subway station with asymmetric load under bidirectional seismic action. International Journal of Safety and Security Engineering 10(4):559-566

Liu CL, Qi SW, Tong LQ, Zhao FS (2004) Stability analysis of slope under earthquake with FLAC3D. Chin J Rock Mech Eng 23(16): 2730-2733

Luo JH, Mi DC, Huang HF, Zhang T, Sun GH, Chen DQ (2020) Intelligent monitoring, stability evaluation, and landslide treatment of a carbonaceous mudstone and shale slope in Guangxi, China. International Journal of Safety and Security Engineering 10(3): 373-379

Marzoratia S, Luzia L, De Amicisb M (2012) Rock falls induced by earthquakes: a statistical approach. Soil Dynamic and Earthquake Engineering 22(3):565-577

Michalowski RL, You L (2000) Displacement of reinforce slopes subjected to seismic loads. J Geotech Geoenviron 126(8):685-694

Nova-Roessig L, Sitar N (2016) Centrifuge model studies of the seismic response of reinforced soil slopes. J Geotech Geoenviron 132(3): $388-400$

Shibata D, Nagao T (2020) Seismic resistant design method for open-type wharf with pneumatic caisson foundation. International Journal of Safety and Security Engineering 10(2):209-218

Taiebat M, Kaynia AM, Dafalias YF (2011) Application of an anisotropic constitutive model for structured clay to seismic slope stability. J Geotech Geoenviron 137(5):492-504

Yan ZX, Zhang XD, Zhang S, Zhang LP, Cao XH (2011) Study on resonance characteristics and natural frequency of slope under bidirectional seismic action. Hydrog Eng Geol 38:46-51

Zhao YGB, Dong YD (2020) Seismic response of reinforced concrete frame-shear wall structure with metal rubber-based damper in coupling beam. Annales de Chimie - Science des Matériaux 44(5):319326

Zhao YGB, Ding PZ, Zhao Y, Yan XW (2019) Mechanical properties of metallic pseudo rubber-silicon rubber composite for three-way seismic isolation. Revue des Composites et des Matériaux Avancés 29(6):341-350 